GRASAS Y ACEITES, 60 (3),

SPECIAL ISSUE, 277-283, 2009,

ISSN: 0017-3495

DOI: $10.3989 / g y a .130808$

\title{
Contributing to interpret sensory attributes qualifying Iberian hams from the volatile profile
}

\author{
By Diego L. García-González, ${ }^{1 *}$ Noelia Tena ${ }^{2}$ and Ramón Aparicio ${ }^{2}$ \\ ${ }^{1}$ Department of Food Science and Agricultural Chemistry, Macdonald Campus of McGill University, \\ Sainte-Anne-de-Bellevue, Quebec, Canada H9X 3V9 \\ ${ }^{2}$ Instituto de la Grasa (CSIC). Padre García Tejero, 4 E-41012 Sevilla, Spain. \\ $\left({ }^{\star}\right.$ Corresponding author: diego.garciagonzalez@mail.mcgill.ca)
}

\section{RESUMEN}

\begin{abstract}
Contribución a la interpretación de atributos sensoriales de calidad en jamones Ibéricos basados en los perfiles de los compuestos volátiles.
\end{abstract}

El estudio se ha llevado a cabo con 8 jamones ibéricos de las principales zonas productoras mediante panel sensorial y análisis de la fracción volátil con SPME-GC. Los últimos análisis fueron llevados a cabo en cuatro localizaciones independientes del jamón (grasa subcutánea, y los músculos bíceps femoris, semitendinosus y semimembranosus) para conocer sus posibles contribuciones parciales al aroma completo del jamón. La relación entre compuestos volátiles y atributos sensoriales ha sido establecida mediante el procedimiento estadístico de la rueda sensorial (SSW), generando una representación gráfica por cada localización. Los compuestos volátiles explican los mismos atributos sensoriales independientemente de la parte del jamón en que se generen aunque los volátiles cuantificados en el músculo semitendinoso y la grasa subcutánea parece que contribuyen ligeramente más que las otras partes al perfil sensorial detectado por los panelistas. Los compuestos volátiles con significación en el aroma del jamón fueron 3-metilbutanol, hexanal, octanol, nonanol y 2-heptanol entre muchos otros, aunque sus contribuciones al aroma varían dependiendo de la localización.

PALABRAS CLAVE: Aroma - Flavor - Jamón ibérico - Quimiometría - Volátiles

\section{SUMMARY}

Contributing to interpret sensory attributes qualifying Iberian hams from the volatile profile.

The study involved the sensory assessment of 8 Iberian hams from the main producer zones and the analysis of their volatile composition by SPME-GC. The latter analysis was carried out independently on 4 well defined locations of the ham (subcutaneous fat, and biceps femoris, semitendinosus, and semimembranosus muscles) in order to know their possible partial contribution to the whole ham aroma. The relation between volatile compounds and sensory attributes was established by the procedure of statistical sensory wheel (SSW), generating 4 different plots, each one of them referring to one of the ham locations. The volatile compounds explain similar information of the sensory attributes independently of the part of the ham from which they are produced although the volatiles quantified in semitendinosus muscle and subcutaneous fat seem to contribute slightly more than the other parts to the sensory profile determined by the panellists. Volatiles compounds with significance in the ham aroma were 3-methylbutanol, hexanal, octanol, nonanol, 2heptanol, among many others, although their contribution to the aroma varies depending on the location.

KEY-WORDS: Aroma - Chemometrics Flavour - Iberian hams - Volatiles

\section{INTRODUCTION}

Dry-cured ham is highly prized for its delicious odour, flavour and texture, not only inside the European producing countries but also in countries as far as Japan and USA. The sensory characteristics of dry-cured hams are not homogeneous but are influenced by both processing conditions and raw meat characteristics. The feature of the pig fattening phase, by acorns or pasture or concentrate feeds (mixtures of cereals and maize at several percentages), combined with the crossbreeding, are the main parameters influencing ham sensory quality and the resulting sensory attributes. The sensory analysis is then the result of evaluating the sensory perceptions and their intensities, after extensive training and assessment work of the sensory assessors; a key aspect of any hypothetical consensus being to avoid sensory attributes that overlap with others or are not defined properly.

Since aroma attributes are descriptions from the sensory assessors' viewpoint, the sensory evaluation of these attributes can differ depending 
on the particular characteristics of the sensory assessment and the panellists. These differences would face with the major drawback in sensory analysis, i.e. the apparent disagreement between the evaluations obtained from different sensory panels (García-Gonzalez et al., 2006). It is, therefore, appropriate to pose the question, firstly, whether assessors from different panels are describing the same or a different attribute when they use the same semantic term; and, secondly, when they use different semantic terms, may they be describing the same attribute?

This problem, which has already been stated in various foodstuffs (Aparicio and Morales, 1995; García-Gonzalez et al., 2006; Pellicano, 2009), cannot be easily resolved unless a definition of the sensory attributes is provided with a frame of reference and it becomes readily grasped by all the assessors when chemical compounds are provided as reference. This potential solution explains why relating aroma sensory attributes and volatile compounds sometimes represents a challenge (Aparicio et al., 1994, 1996; García-Gonzalez et al., 2008).

Aroma perception is not, however, induced by a simple stimulus but it is often a complex process in which each aroma is characterized by a distinct composition of a certain number of key volatiles (Aparicio et al., 1996). A good numerical relationship (e.g. $R^{2}>0.75$ ) between volatile compounds and sensory attributes does not automatically imply that the relative amount of a compound quantified in the food has a sensory impact on the food since only those compounds in concentrations higher than their odour threshold are odour-active (Luna et al., 2006a). Little research has been dedicated to this field in fat products (Carrapiso et al., 2002; Morales \& Tsimidou, 2000; García-González et al., 2008) though several studies have been independently conducted on ham sensory attributes (Pastorelli et al., 2003; Ruiz et al., 2002) and on the volatiles of dry cured hams (Ramirez and Cava, 2007; Andres et al., 2002; Sanchez-Peña et al., 2005; Timón et al., 2001; Gaspardo et al., 2008; Pham et al., 2008).

Authors agree that the aroma is perhaps the most important quality parameter of dry cured hams to be studied. However dry cured ham is a solid food and its sensory evaluation is difficult to deal with, since the strength of the aroma perception is affected by the release of volatile compounds during mastication. In order to explain the sensory attributes from the flavours release during eating it is necessary to assume that only those volatiles whose concentrations in the food material exceed their odour threshold have been considered in this study (Buettner and Schieberle, 2000) but keeping in mind that the perceived intensity of an individual volatile is almost always higher than the sum of the intensities of the volatiles that constitute the natural mixture that defines a particular odour (Laing et al., 1984). Furthermore, ham samples are heterogeneous and, in consequence, the variability of the analytical results is related with the amounts of muscles and subcutaneous fat in every sample
(Luna et al., 2006b). It is well-established that chemical changes occurring in different muscles during the ripening of hams influence the ham aroma and flavour (Ruiz et al., 1998). It is only recently that the contribution of the most important parts of the hams (subcutaneous fat, and biceps femoris, semimembranosus and semitendinosus muscles) to their aroma and flavour has begun to be elucidated (Luna et al., 2006b; Monin et al., 1997; Sánchez-Peña et al., 2005).

The special characteristics of the Iberian pigs concerning breed, feeding, slaughtering weight and prolonging curing process - produce a meat - drycured Iberian ham - with particular quality traits (e.g. high intramuscular fat), an ample variety of sensations in the flavour profile and, hence, an excellent consumer acceptance. Dry-cured Iberian hams, a foodstuff produced in southwest of Spain, is by large the most valuable meat product in Spain.

The aim of this work is to carry out a complete study of the relationship between 13 odour and flavour sensory attributes and 27 volatile compounds in 8 Iberian hams from diverse geographical origins. The odour thresholds were used to select those volatiles with sensorial significance prior to correlating them with the sensory attributes by the statistical sensory wheel. The volatiles qualifying four parts of the hams (subcutaneous fat, and semitendinosus, semimembranosus and biceps femoris muscles) were used to explain the whole flavour of the Iberian hams.

\section{MATERIALS AND METHODS}

\subsection{Samples}

A total of 8 Iberian hams - Iberian $\times$ DurocJersey with a minimum of $50 \%$ Iberian pig- from several geographical origins was used for this study. Iberian pigs were fattened with acorn and pasture as main food source, following the traditional extensive production system of this kind of pigs in southern Spain. All the hams were processed by local manufacturers using the traditional method of each geographical origin: Badajoz, Cáceres, Córdoba, Huelva y Salamanca. The hams were matured for around 600 days, as total time of the curing process, according to the information reported by the producers (Giraud, 2005).

The samples were stored in vacuum plastic bags at $-5{ }^{\circ} \mathrm{C}$ until they were required for the sensory and chemical studies.

These samples somewhat reproduce the actual variability in dry cured ham features that the consumer can find in the market.

\subsection{Reagents}

All the chemical compounds were purchased from Fluka-Sigma-Aldrich (St. Louis, MO). 
Table 1

Codes and sensory attributes evaluated in Iberian hams

\begin{tabular}{lll}
\hline Code & Sensory attributes & mean \pm std \\
\hline F1 & Cured ham odour & $5.80 \pm 0.29$ \\
F2 & Rancid odour & $3.18 \pm 0.31$ \\
F3 & Acorn odour & $1.27 \pm 0.08$ \\
F4 & Smoke odour & $1.01 \pm 0.01$ \\
F5 & Mouldy odour & $2.48 \pm 0.16$ \\
F6 & Salty taste & $4.39 \pm 0.21$ \\
F7 & Rancid taste & $2.43 \pm 0.39$ \\
F8 & Cured ham flavour & $5.15 \pm 0.28$ \\
F9 & Acorn flavour & $1.27 \pm 0.06$ \\
F10 & Raw meat flavour & $1.20 \pm 0.09$ \\
F11 & Pungent flavour & $2.07 \pm 0.12$ \\
F12 & Fat rancid flavour & $5.33 \pm 0.53$ \\
F13 & Fat pungent flavour & $4.29 \pm 0.34$ \\
\hline
\end{tabular}

\subsection{Gas-chromatography (SPME-GC)}

A sample of approximately $350 \mathrm{~g}$ of the part located along and behind the femur was collected from each one of the hams, composed essentially of subcutaneous fat and biceps femoris, semimembranosus and semitendinosus muscles. Three grams representative of the ham portion, previously minced to increase the interface between the ham and the vapour phase during the concentration step, were placed into $20 \mathrm{ml}$ glass vials tightly capped with a PTFE septum and left for $10 \mathrm{~min}$ at $40^{\circ} \mathrm{C}$ to allow equilibration of the volatiles in the headspace. The septum covering each vial was then pierced with a solid-phase microextraction (SPME) needle and a Carboxen/PDMS/DVB fibre (Supelco, Bellefonte, PA) exposed to the headspace for $180 \mathrm{~min}$ (Gianelli et al., 2002). When the process was completed, the fibre was inserted into the injector port of the GC for $5 \mathrm{~min}$ at $260^{\circ} \mathrm{C}$ using the splitless mode. The temperature and time were automatically controlled by a Combipal (CTC Analytics AG, Zwingen, Switzerland) using the Workstation v.5.5.2 (Varian, Walnut Creek, CA) software.

The volatile compounds were analysed using a DB-WAX column (J\&W Scientific, Folsom, CA; $60 \mathrm{~m}$ $\times 0.25 \mathrm{~mm}$ id $\times 0.25 \mu \mathrm{m}$ film thickness) installed on a Varian 3900 gas chromatograph (Varian, Walnut Creek, CA) with a flame ionization detector. The carrier gas was hydrogen. The oven temperature was held at $40^{\circ} \mathrm{C}$ for $4 \mathrm{~min}$ and programmed to rise $1^{\circ} \mathrm{C} / \mathrm{min}$ to a temperature of $91^{\circ} \mathrm{C}$, and then to rise $10{ }^{\circ} \mathrm{C} / \mathrm{min}$ to a final temperature of $201^{\circ} \mathrm{C}$, where it was held for $10 \mathrm{~min}$. Each sample was analysed in triplicate.

The identification of volatile compounds by GC-MS was carried out on a GC8000 (Carlo Erba, Milano, Italy) gas chromatograph coupled to a MSD-800 (Fisons, Manchester, UK) mass-selective detector. Column and analytical conditions were identical to those described for gas chromatography with the exception of the carrier gas that was helium (head pressure $15 \mathrm{psi}$ ). Volatile compounds were tentatively identified by the library MassLab v.1.3. (VG MassLab, Altrincham, UK).

The content of each volatile compound was calculated from the FID area and expressed as area units. A solution of 4-methyl-2-pentanol (1.2 $\mathrm{mg} / \mathrm{kg}$ ) was used as external standard in order to standardise the results of all the analyses. Thus, the amount $(\mathrm{mg} / \mathrm{kg})$ of each volatile compound was computed by relating the peak area of the volatile compound to the area of the standard and taking into account the sample weight and the response factor of each volatile (García-González et al., 2008).

\subsection{GC-olfactometry (GC-O)}

GC-olfactometry (GC-O) was applied to assess the aroma notes corresponding to ham volatile compounds. The effluent of the GC column was split 1-10 to the detector and the sniffing port, respectively. Three assessors with a large experience of odour recognition and of sniffing drycured hams carried out the evaluation. Elution of each aroma compound through the sniffing port was recorded by writing the beginning and end of the entire sensation of any odorant as well as its odour properties. The final aromagram (sensory description versus Rt) is the result of merging the information from the individual analyses of the assessors.

\subsection{Odour threshold of volatile compounds}

Fully deodorised edible oil was the matrix for the assessment of the odour threshold values; the absence of volatile compounds in the matrix was checked by the SPME-GC procedure described above. The sensory assessment was carried out in a test room arranged for evaluating sensory characteristics. Three assessors with a large experience of odour recognition and of sniffing virgin olive oils carried out the evaluation. Three samples were presented to the assessors following the triangle test whose results were statistically analysed. Each sample $(15 \mathrm{ml})$ was kept in standardised glasses at $29^{\circ} \mathrm{C} \pm 2{ }^{\circ} \mathrm{C}$ for $15 \mathrm{~min}$ and then tested. The samples were diluted until none of the assessors was able to classify the samples by odour intensity. The odour activity values (OAVs) of the volatile compounds, defined as the ratio of the concentration to the odour threshold (Aparicio and Morales, 1998), were calculated to determine their sensory significance. Thus, only those volatiles with $\mathrm{OAV} \geqslant 1.0$ contribute to the sensory perceptions.

\subsection{Statistical analysis}

Univariate and multivariate algorithms have been used by means of Statistica (Statsoft, 2001). The implementation of statistical sensory wheel 
(SSW) was carried out by applying the methodology described in Aparicio et al. (1996).

\section{RESULTS AND DISCUSSION}

The explanation of the food aroma by means of the volatile composition of the product has the additional difficulty of overlapping information in both sensory attributes and volatile compounds. Thus, sensory attributes can have been subjected to a non proper definition or a misunderstanding by the panellist. This confusion would imply that some of the attributes may give the same information than others. On the other hand, part of the high variety of volatile compounds produced during the maturation follows the same trend over time and therefore their concentration may be mathematically correlated. Thus, under the consideration of these two possible sources of error, a procedure consisting of two steps was applied to relate the particular flavour of Iberian hams with their profile of volatiles. Firstly, multivariate and univariate studies of the dataset of sensory attributes were planned to determine the possible mathematical overlaps between the descriptors, while the second step was focused on the elucidation of the relationship between sensory attributes and volatile compounds by statistical procedures.
Table 1 shows the flavour attributes evaluated by panellists and their mean intensities when evaluated the hams (Garcia-Gonzalez et al., 2006); the intensities of almost all the flavour attributes (the exception was cured ham flavour) and many of odour attributes (exceptions were smoke and mouldy odour) would allow distinguishing Iberian hams from white hams (Sánchez-Peña et al., 2005). Concerning the relationship between the sensory perceptions, the highest correlations were detected between the attributes related to the rancid perception. Thus, fat rancid flavour was highly correlated with rancid odour (0.89) and rancid taste (0.86), and fat pungent flavour with rancid odour (0.85). The correlations between the pairs of perceptions of the same attribute (e.g., odour and flavour) were not high with the exception of rancid (0.83) and cured hams (0.72).

The study of the sensory attributes and their relationship was followed with the inclusion of the volatile compounds into the dataset to examine the relation between both kinds of information. Table 2 shows the volatile compounds quantified in the samples that have an OAV $\geqslant 1$ and hence can contribute to aroma profile of Iberian hams with sensory perceptions like those detected by GC-O. However, most attempts of correlating flavour scores and volatile contents have to be based on

Table 2

Codes, relative retention times and concentration (mean \pm std) of the volatile compounds quantified in Iberian hams

\begin{tabular}{cclcll}
\hline Code & $\mathbf{R t}$ & Volatile compound & Iberian & Odour threshold & \multicolumn{1}{c}{ GC-O } \\
\hline 1 & 0.20 & octane & $3.000 \pm 0.413$ & 0.94 & Sweety, alkane \\
2 & 0.29 & 3-methylbutanal & $0.380 \pm 0.060$ & 0.08 & Nutty, fruity, cheesy, salty \\
3 & 0.46 & Q-pinene & $0.080 \pm 0.017$ & $0.018^{\text {a }}$ & Sharp, pine \\
4 & 0.60 & dimethyl disulfide & $0.018 \pm 0.003$ & 0.012 & Cauliflowers, vegetable \\
5 & 0.64 & hexanal & $3.760 \pm 0.644$ & 0.08 & Green, grassy, fatty \\
6 & 0.90 & butanol & $0.148 \pm 0.008$ & 0.038 & Fruity, medicinal \\
7 & 1.05 & 2-heptanone & $1.240 \pm 0.277$ & 0.30 & Spicy, nutty, blue cheese \\
8 & 1.06 & heptanal & $1.470 \pm 0.209$ & 0.50 & Fatty, greasy, ham-like \\
9 & 1.09 & limonene & $2.680 \pm 0.559$ & 0.25 & Citric, fresh \\
10 & 1.21 & 3-methylbutanol & $5.270 \pm 1.148$ & 0.10 & Woody, nutty, pleasant, green \\
11 & 1.31 & 2-pentyl furane & $0.940 \pm 0.218$ & 0.10 & Green fruity \\
12 & 1.43 & octen-3-one & $0.630 \pm 0.081$ & 0.01 & Spicy, mushroom, dirty \\
13 & 1.46 & pentanol & $1.258 \pm 0.060$ & 0.47 & Pungent, strong, balsamic \\
14 & 1.61 & 2-octanone & $0.720 \pm 0.118$ & 0.51 & Fruity, floral, green, fresh \\
15 & 1.63 & octanal & $7.380 \pm 1.104$ & 0.32 & Meat-like, green, fresh \\
16 & 1.84 & E-2-heptenal & $0.710 \pm 0.186$ & 0.05 & Green, fatty, fruity, almonds \\
17 & 1.89 & 2-heptanol & $0.700 \pm 0.132$ & 0.01 & Oily, sweety \\
18 & 2.09 & hexanol & $4.100 \pm 0.585$ & 0.40 & Fruity, green \\
19 & 2.30 & 2-nonanone & $1.690 \pm 0.523$ & 0.10 & Floral, fruity, blue chesse \\
20 & 2.33 & nonanal & $4.330 \pm 0.674$ & 0.15 & Rancid, fatty \\
21 & 2.55 & E-2-octenal & $2.470 \pm 0.578$ & 0.004 & Leaves, pungent, fatty, fruity \\
22 & 2.76 & 1-octen-3-ol & $1.660 \pm 0.213$ & 0.001 & Mushroom-like, earthy, dust \\
23 & 3.11 & benzaldehyde & $1.780 \pm 0.210$ & 0.06 & Bitter almonds, penetrating \\
24 & 3.22 & E-2-nonenal & $3.875 \pm 0.922$ & 0.15 & Fatty, waxy \\
25 & 3.47 & octanol & $0.980 \pm 0.115$ & 0.027 & Fatty, sharp \\
26 & 3.94 & butanoic acid & $0.611 \pm 0.092$ & 0.65 & Cheesy, rancid \\
27 & 4.13 & nonanol & $0.260 \pm 0.039$ & 0.28 & Fatty green \\
\hline
\end{tabular}

Odour threshold values (mg/k) and sensory descriptions obtained by GC-olfactometry (GC-O).

Note: Rt, retention time.

a Nagata (1990). 
mathematical procedures that take into account the possible synergy and antagonism between volatile compounds that can contribute to sensory perceptions (OAV $\geqslant 1)$. In consequence, it is of great interest to ascertain the relationships between sensory attributes and the volatiles responsible for them. An appropriate method would need to gather as much information from sensory and chemical quantification as possible to reveal the basic flavour notes from a set of sensory attributes and the volatile compounds responsible for them.

One possible approach is the statistical sensory wheel (SSW) that has had a great success in qualifying sensory attributes of virgin olive oil (Aparicio et al., 1996). As the flavour of dry cured hams has been already described by different
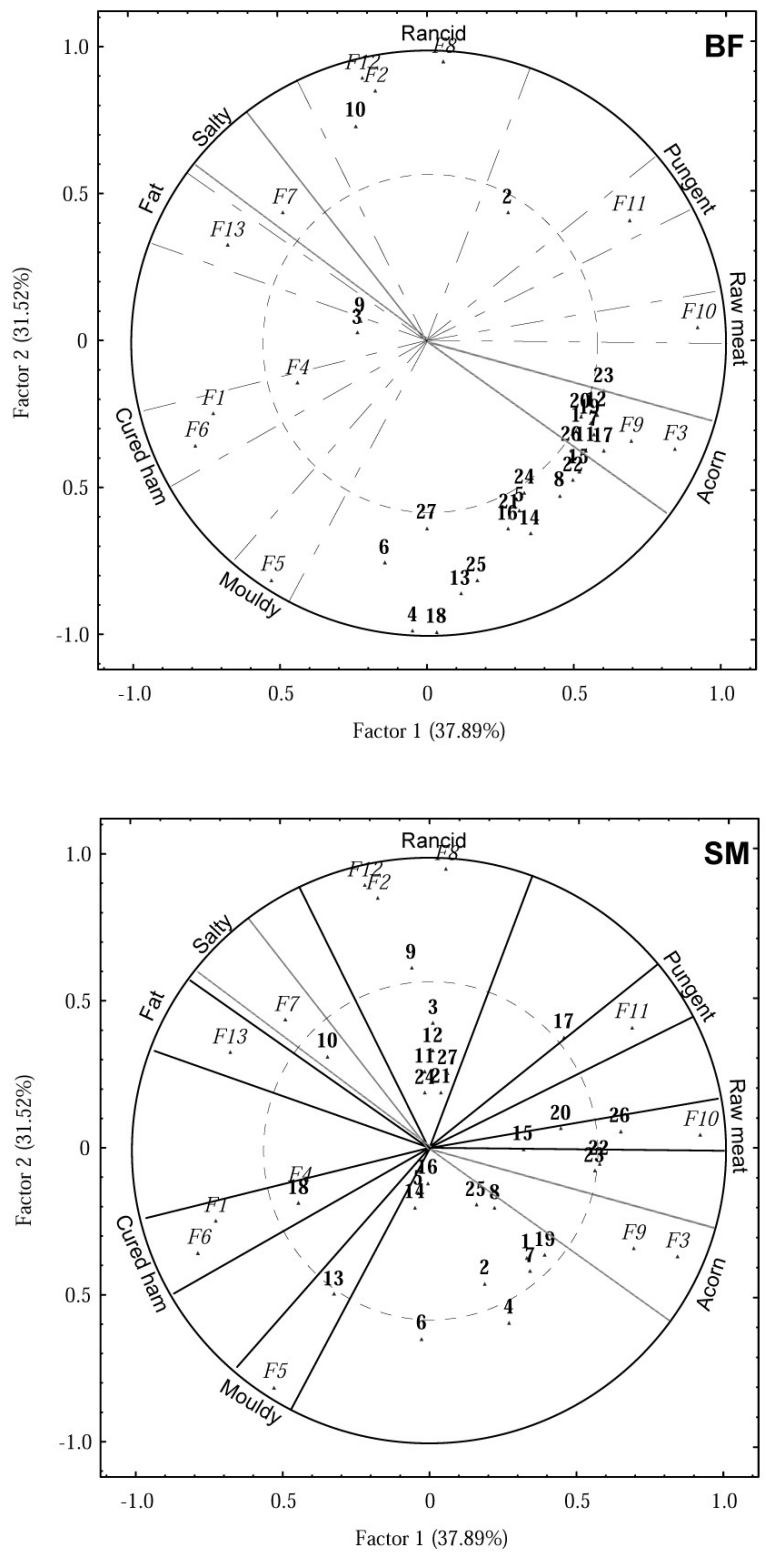

sensory attributes (García-González et al., 2006), the projection of volatile compounds onto SSW can give a plausible explanation of the relationship between sensory attributes and volatile compounds.

The statistical sensory wheel of Iberian hams (Figure 1) was divided into 8 sectors that correspond to eight perceptions: rancid, pungent, raw meat, acorn (nutty), mouldy, cured ham, fat flavour and salty. The sectors were calculated taking into account the circular standard deviation index of each perception (Aparicio and Morales, 1995) after evaluating the samples.

Since SSW has been stated as the mathematical representation of the Iberian ham flavour matrix, and volatile compounds have been described as responsible for the flavour, a procedure that gathered both datasets would show whether the
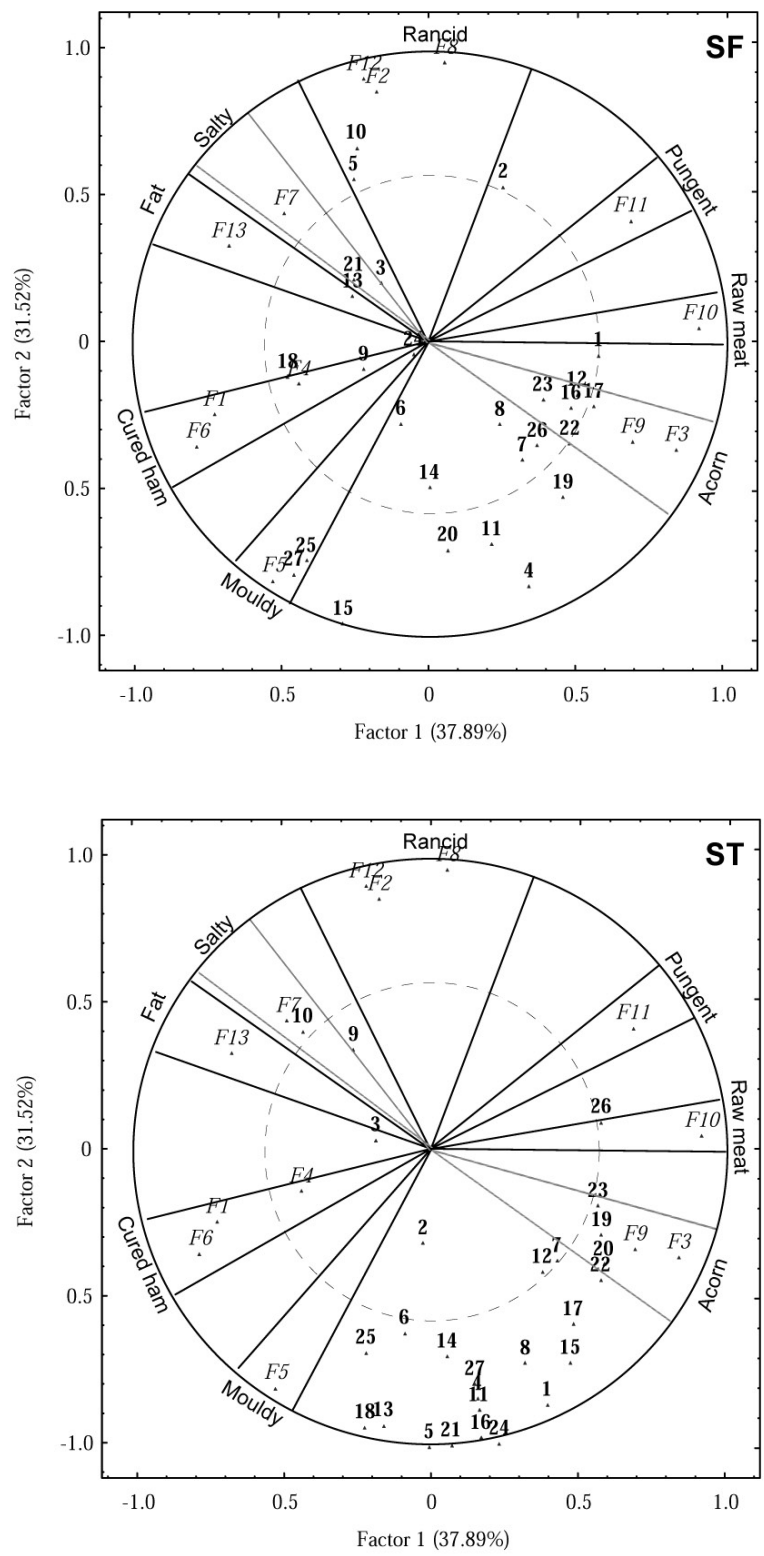

Figure 1.

Plots of the statistical sensory wheel (SSW) of sensory attributes on which the volatiles compounds quantified in four parts of the Iberian hams (subcutaneous fat -SF-, biceps femoris -BF-, semitendinosus -ST- and semimembranous -SMmuscles) were projected. Codes are described in Tables 1 and 2. 
sensory wheel sectors were mathematical artifacts, or if they were indicating the volatiles responsible for basic flavour perceptions of Iberian hams. Ham samples, however, are not homogeneous but they have four main parts (subcutaneous fat, and bicep femoris, semitendinosus, and semimembranosus muscles) and hence the volatile quantified independently in these four parts of the samples (Sánchez-Peña et al., 2005) were projected onto the area defined on the SSW so resulting four flavour SSW plots, one per each part.

The projection of the volatiles means the calculation of the coordinates $(x, y)$ of each volatile in the flavour SSW. Coordinates were computed by determining the correlation of each volatile compound with the first two factors of SSW. Thus, all the volatiles are standardized by the set of selected attributes representing different kinds of Iberian hams.

The position of volatiles in the sensory wheel determines their information content; the distance of a volatile to the circle centre points out how much it contributes to flavour. Thus, the volatiles near the centre of the circle contribute less than those placed near the perimeter. Furthermore, the vicinity of a volatile to an attribute indicates a good correlation between them, from a mathematical viewpoint, but also its sensory qualification according to the sensory attributes surrounding it. In consequence, the volatiles inside the SSW sector of a sensory perception should be better correlated with this perception than those located outside.

Figure 1 shows the projection of the volatiles quantified in the four parts of the hams (SánchezPeña et al., 2005) onto the SSW. The volatiles quantified in the subcutaneous fat (Figure 1-SF) seem to contribute to rancid (3-methylbutanol, hexanal) and mouldy (octanol, nonanol) sensory perceptions. There are several volatiles inside the acorn sector but only 2-heptanol seems to contribute this perception in Iberian hams. The concentration of all these volatiles is higher in Iberian hams than other dry-cured hams (García-Gonzalez et al., 2008). Eight volatiles (numbered 4, 5, 10, 11, 15, 20, 25, 27) quantified in the subcutaneous fat seems to influence the whole Iberian flavour.

Figure 1-BF shows that in biceps femoris almost all the volatiles contribute to Iberian flavour but this contribution is not equally distributed between the eight perceptions, but they are mainly placed in the sectors of acorn and, partially, rancid perceptions; the latter possibly due to the infiltrated fat in this muscle. No volatile is clustered inside the acorn sector when the volatiles of the semimembranosus muscle were projected onto SSW (Figure 1-SM). Butanoic acid seems to contribute to raw meat perception whose concentration in Iberian hams is slightly higher (García-González et al., 2008). Several volatiles are inside the rancid sector although most of them do not seem to influence too much on the final flavour. Most of the volatiles quantified in the semitendinosus muscle (Figure 1ST) are placed outside the sectors of the eight perceptions although many of them are placed between both circles and they would contribute to the flavour of Iberian hams.

The information collected shows that all the parts of the hams contribute to the whole Iberian flavour. The percentage with which their volatiles contributes to flavour varies between $52.15 \%$ of semimembranosus and $83.2 \%$ of semitendinosus muscles although there is a certain redundancy in the information reported by the volatiles that oscillates between $58.02 \%$ (biceps femoris) and $44.12 \%$ (subcutaneous fat). This information means, from a mathematical viewpoint, the volatile compounds explain similar information of the sensory attributes independently of the part of the ham from which they are produced although the semitendinosus muscle and subcutaneous fat seem to be slightly more relevant.

The relationship between sensory attributes and volatiles does not show great disagreements with a previous work (García-González et al., 2008) in which 41 dry-cured hams (31 being white hams) were analysed. The fact that ham is not a homogeneous product and the percentages of the fat and muscle in the samples could have influenced the differences.

This study shows the potential importance of the mathematical tools to elucidate the role of volatile compounds in the sensory assessment of drycured hams. However, the high complexity of the dry cured ham flavour and the heterogeneity of this solid food made necessary to re-analyse the results due to the limited number of Iberian hams of this study. Further studies are being carried out for a better understanding of the role of the muscles and the subcutaneous fat in the whole flavour of Iberian hams.

\section{REFERENCES}

Andres Al, Cava R, Ruiz J. 2002. Monitoring volatile compounds during dry-cured ham ripening by solidphase microextraction coupled to a new directextraction device. J. Chromatogr. A 963, 83-88.

Aparicio R, Alonso MV, Morales MT, Calvente JJ. 1994. Relationship between the COI Test and other sensory profiles by statistical procedures. Grasas Aceites 45, 26-41.

Aparicio R, Morales MT.1995. Sensory wheels: A Statistical Technique for Comparing QDA Panels: Application to Virgin Olive Oil. J. Sci. Food Agric. 67, 247-257.

Aparicio R, Morales MT, Alonso V. 1996. Relationship between Volatile Compounds and Sensory Attributes by Statistical Sensory Wheel. J. Amer. Oil Chem. Soc. 73, 1253-1264.

Buettner A, Schieberle P. 2000. Stable isotope dilution assays for the quantification of odour-active thiols in hand-squeezed grapefruits juices (Citrus paradisi Mafayden). In P Schieberle \& H.H Engel, Frontiers of Flavour Science, Proceedings of the $9^{\text {th }}$ Weurman Flavour Research Symposium, pp 132-134 
Carrapiso Al, Jurado A, Timón AL, García C. 2002. OdorActive Compounds of Iberian Hams with Different Aroma Characteristics. J. Sci. Food Agric. 50, 64536458.

Giraud G. 2005. Final report European project "Typical Food Products Europe: Consumer Preference and Objective Assessment QLK1-CT2002-02225 (TYPIC)". The Commission of European Communities, Brussels (Belgium)

García-González DL, Roncales P, Cilla I, del Río S, Poma JP, Aparicio R. 2006. Interlaboratory evaluation of drycured hams (from France and Spain) by assessors from two different nationalities. Meat Sci. 73, 521-528

García-González DL, Tena N, Aparicio-Ruiz R, Morales MT. 2008. Relationship between sensory attributes and volatile compounds qualifying dry-cured hams. Meat Sci. 80, 315-325

Gaspardo B, Procida G, Toso B, Stefanon B. 2008. Determination of volatile compounds in San Daniele ham using headspace GC-MS. Meat Sci. 80, 204-209

Gianelli MP, Flores M, Toldrá F. 2002. Optimisation of solid phase microextraction (SPME) for the analysis of volatile dry-cured ham. J. Sci. Food Agric. 82, 17031709

Laing DG, Panhuber H, Willcox ME, Pittman EA. 1984 Quality and intensity of binary odour mixtures. Physiology \& Behavior 33, 309-319.

Luna G, Morales MT, Aparicio R. 2006a. Characterization of 39 varietal virgin olive oils by their volatile composition. Food Chem. 98, 243-252.

Luna G, Aparicio R, García-González DL. 2006b. A tentative characterization of white dry-cured hams from Teruel (Spain) by SPME-GC. Food Chem. 97, 621-630.

Monin G, Marinova P, Talmant A, Martin JF, Cornet M, Lanore D, Grasso F. 1997. Chemical and structural changes in dry-cured hams (Bayonne hams) during processing and effects of the dehairing technique. Meat Sci. 47, 29-47.

Morales MT, Tsimidou M. 2000. The role of volatile compounds and polyphenols in olive oil sensory quality. In: Handbook on Olive Oil: Analysis and
Properties (Eds. J. Harwood and R. Aparicio). Aspen Gaitherburg MA, pp. 393-458.

Nagata Y. 1990. Measurement of odor threshold by triangle odor bag method. Bulletin Japan Environ. Sanit. Center 17, 77-89.

Pastorelli G, Magni S, Rossi R, Pagliarini E, Baldini P, Dirinck P, Van Opstaele F, Corino C. 2003. Influence of dietary fat, on fatty acid composition and sensory properties of dry-cured Parma ham. Meat Sci. 65, 571-580.

Pellicano MP. 2009. Results of MAC-Oils project on the organoleptic properties of edible oils. In European project MAC-OILS final public conference. January 2009, Rome Italy

Pham AJ, Schilling MW, Mikel WB, Martin JM, Coggins PC. 2008. Relationships between sensory descriptors, consumer acceptability and volatile flavor compounds of American dry-cured ham. Meat Sci. 80, 728-737

Ramírez R, Cava R. 2007. Volatile profiles of dry-cured meat products from three different Iberian $\times$ Duroc genotypes. J. Agric. Food Chem. 55, 1923-1931.

Ruiz J, Ventanas R, Cava R, Timón ML, García C. 1998. Sensory characteristics of Iberian ham: influence of processing time and slice location. Food Res. Int. 31, 53-58.

Ruiz J, García C, Muriel E, Andrés Al, Ventanas J. 2002. Influence of sensory characteristics on the acceptability of dry-cured ham. Meat Sci. 61, 347-354

Sánchez-Peña CM, Luna G, Aparicio R. 2005. Characterization of French and Spanish dry-cured hams: influence of the volatiles from the muscles and the subcutaneous fat quantified by SPME-GC. Meat Sci. 69, 635-645.

Statsoft. 2001. STATISTICA, release 6.0. Tulsa, OK, Statsoft Inc.

Timón ML, Ventanas J, Carrapiso Al, Jurado A, García C. 2001. Subcutaneous and intermuscular fat characterisation of dry-cured Iberian hams. Meat Sci. 58, 85-91

Recibido: 26/12/08 Aceptado: 5/2/09 